\title{
Randomized controlled trials in frontotemporal dementia: cognitive and behavioral outcomes
}

\author{
Justin B Miller*, Sarah J Banks, Gabriel C Léger and Jeffrey L Cummings
}

\begin{abstract}
Progress has been made in understanding the genetics and molecular biology of frontotemporal dementia (FTD). Targets for intervention have been identified, therapies are being developed, and clinical trials are advancing. A major challenge for FTD research is that multiple underlying pathologies can be associated with heterogeneous phenotypes. The neuropsychological profiles associated with FTD spectrum disorders often include executive dysfunction, language impairments and behavioral disturbance. Behavioral variant FTD is characterized by an initial presentation of changes in personality, behavior and/or emotion, which are often difficult to objectively capture using traditional neuropsychological measures. The two principal language variants of FTD are Progressive Nonfluent Aphasia (PNFA) with predominant agrammatic/non-fluent impairments and Semantic Dementia (SD) with semantic impairments and visual agnosia. Selection of appropriate endpoints for clinical trials is critical to ensure that the measures are adequately sensitive to detect change, yet specific enough to isolate signal from noise, and acceptable to regulatory agencies. Given the anticipated potential for small effect sizes, measures must be able to identify small incremental changes over time. It is also imperative that the measures provide adequate coverage of the constructs or behaviors of interest. Selected outcome measures should be suitable for repeat administration, yet relatively robust to practice effects to ensure that observed changes reflect true signal variance and not residual effects due to repeated measurement or poor reliability. To facilitate widespread adoption as an endpoint, measures should be readily accessible. We provide several examples of potential global, composite, and individual cognitive measures, as well as behavioral measures promising for FTD trials. Development and application of appropriate trial outcomes is critically important to success in advancing new treatments for FTD patients.
\end{abstract}

Keywords: Frontotemporal dementia, Primary endpoints, Secondary endpoints, Randomized controlled trial, Methods

Frontotemporal dementia (FTD) is a clinically and biologically diverse neurodegenerative disease that rivals the prevalence of Alzheimer's disease (AD) in adults younger than 65 [1]. A major challenge for FTD research is that there are multiple underlying pathologies [2,3], and any of the identified pathologies can be associated with heterogeneous phenotypes depending upon the lesion type, load, and distribution [4,5]. Classifications of FTD are evolving based on genotype, protein abnormality, and phenotype. The neuropsychological profile associated with FTD spectrum disorders often includes executive dysfunction and language impairments. Behavioral variant frontotemporal dementia (bvFTD) is characterized by an initial presentation

\footnotetext{
*Correspondence: millerj4@ccf.org

Cleveland Clinic, Lou Ruvo Center for Brain Health, 888 W. Bonneville Ave, Las Vegas, Nevada 89106, USA
}

(c) 2014 Miller et al.; licensee BioMed Central Ltd. This is an Open Access article distributed under the terms of the Creative Commons Attribution License (http://creativecommons.org/licenses/by/4.0), which permits unrestricted use, distribution, and reproduction in any medium, provided the original work is properly credited. The Creative Commons Public Domain Dedication waiver (http://creativecommons.org/publicdomain/zero/1.0/) applies to the data made available in this article unless otherwise stated.

of changes in personality, behavior and/or emotion which are often difficult to objectively capture using traditional neuropsychological measures. There are two principal language variants associated with FTD: Primary Progressive Nonfluent Aphasia (PPNA) with predominant agrammatic/ non-fluent impairments or Semantic Dementia (SD) with fluent verbal output and semantic impairments [6]. A third language variant, Logopenic progressive aphasia, is occasionally associated with FTD, although most cases with aphasia of the logopenic type are due to $\mathrm{AD}[6]$.

Improved understanding of the neurobiology of FTD has led to the identification of candidate therapies that address the underlying pathophysiology associated with this group of disorders [7]. Clinical trials are anticipated as promising agents are introduced to human populations to assess efficacy. Given the phenotypic diversity of FTD, 
selection of appropriate endpoints for clinical trials is challenging and making good choices is critical to ensure that the trial measures are adequately sensitive to detect change, yet specific enough to isolate signal from noise, and acceptable to regulatory agencies (i.e., Food and Drug Administration, FDA; European Medicines Agency, EMA). The primary aim of this paper is to discuss considerations for identification and selection of appropriate cognitive and behavioral endpoints (e.g., domains of function) for use in clinical trials. It is not our intent to be prescriptive about specific measures or endpoints to employ, but to generate recommendations and identify critical factors to consider during trial planning to facilitate selection of neuropsychological endpoints. There are a number of biomarkers that should also be considered for use in randomized clinical trials (RCTs) for FTD, however, discussion of such measures is beyond the scope and aims of this paper. Here, we restrict our emphasis to the cognitive and behavioral phenotypes, relevant to selecting outcomes for RCTs.

\section{FDA Recommended Outcomes in RCTs}

In order to promote uniformity across drug development for dementia disorders, the United States FDA mandates several essential outcome types that must be included in dementia-related trials. Although the FDA does not have requirements for specific tests or measures that need to be included, nonbinding recommendations are made regarding the domains to be assessed. In AD trials --- which function as a guide to how to conduct FTD trials --- the FDA requires dual outcomes: a measure of the core cognitive features of the disorder and a global or functional measure to determine the clinical meaningfulness of any therapeutic benefit [8]. Often based on clinician ratings, global measures attempt to provide an overall quantitative estimate of cognition, behavior, and daily functioning and are frequently used as a co-primary endpoint [9]. Examples of commonly used global measures in AD trials include the Clinical Dementia Rating (CDR) [10] and the Clinicians' Interview-Based Impression of Change (CIBIC) [9]. An alternative indicator of clinical meaningfulness is the use of a measure of activities of daily living such as the Alzheimer's Disease Cooperative Study (ADCS) Activities of Daily Living (ADL) scale [11] or the Disability Assessment for Dementia (DAD) [12].

These global or functional measures are complemented by a measure of the core cognitive components of the dementia syndrome. In $\mathrm{AD}$, the Alzheimer's Disease Assessment Scale - Cognitive Portion (ADAS-Cog) [13] is the most commonly used neuropsychological assessment. This tool, however, lacks executive measures, emphasizes capture of the memory impairment characteristic of $\mathrm{AD}$ and does not explore language in depth, limiting its usefulness for FTD clinical trials. Alternative measures sensitive to the specific abnormalities found in FTD are needed.

Secondary outcome measures are commonly used in dementia trials to assess behavioral [14] and economic outcomes [15]. These secondary outcomes provide additional insight into drug effects but are not included in the package insert description of an approved agent.

Although FTD has known and identifiable pathologies and several potential biomarkers [16], use of biomarkers as a surrogate for clinical benefit is currently not available in dementia syndromes [17]. Until such evidence exists, measures of cognition will remain the central marker of change and clinical benefit.

\section{Current summary of randomized clinical trials in FTD}

There have been relatively few randomized clinical trials (RCTs) in FTD, and those that have been conducted have been small and often inconclusive, particularly with regard to cognition. A review of RCTs published in the last decade indicates that several existing pharmacological interventions may be beneficial for reducing behavioral disturbances in FTD, however, none of the reviewed studies yielded any benefit for improving cognition [18] and some have shown undesirable effects $[7,19]$. A summary of the endpoints reported in the published trials is presented in Table 1.

Among the reviewed trials, the Clinical Global Impression (CGI) and its subscales specific to change (CGI-C), improvement (CGI-I) and severity (CGI-S) was used in 3 trials [7,22,25], and the CIBIC with caregiver input $(\mathrm{CIBIC}+)$ was used in one as a global measure [19]. Assessment of cognition was much more variable across the trials, with little evidence of uniformity in either domain coverage or assessment approach. Memory and executive functioning were the most commonly assessed domains. Three studies assessed episodic memory explicitly via subscales of composite batteries (e.g., Dementia Rating Scale; DRS [27]; Repeatable Battery for the Assessment of Neuropsychological Status; RBANS [28]) and six of nine studies evaluated some component of executive functioning, though there was no standard approach. The Mini-Mental Status Exam (MMSE) [29] was the most frequently administered cognitive measure, with use in five of nine trials. Several studies employed a battery of cognitive tests, including the Cambridge Neuropsychological Test Automated Battery (CANTAB) and the DRS, which were the second most frequently used measures, appearing in two trials each $[19,21,23,25]$. The RBANS was employed in one trial [24]. The diversity of approaches observed in these trials suggests that a consensus has not been reached on how best to assess FTD spectrum disorders in RCTs.

Much greater uniformity was apparent across trials with regard to behavioral endpoints, and most trials employed 
Table 1 Summary of published endpoints in randomized controlled trials in frontotemporal dementia

\begin{tabular}{|c|c|c|c|c|}
\hline Study & Sample size & Global endpoints & Cognitive endpoints & Behavioral endpoints \\
\hline Moretti, R. et al. [20] & 16 & --- & $\begin{array}{l}\text { MMSE, Ten Point Clock Test, Proverb } \\
\text { Interpretation Tasks, Stroop Test }\end{array}$ & $\mathrm{NPI}, \mathrm{CIRS}, \mathrm{CSDD}, \mathrm{BEHAVE}-\mathrm{AD}$ \\
\hline Deakin, J.B. et al. [21] & 10 & --- & CANTAB*, Verbal fluency, Digit Span & $\mathrm{NPI}, \mathrm{CBI}$ \\
\hline Lebert, F. [22] & 26 & CGI-I & MMSE & NPI \\
\hline Rahman, S. [23] & 8 & --- & NART, MMSE, CANTAB**, Cambridge Gamble Task & --- \\
\hline Huey, E.D. [24] & 8 & --- & RBANS & NPI \\
\hline Kertesz, A. [25] & 36 & CGI-S, CGI-I & WAB, MMSE, DRS & $\mathrm{FBI}, \mathrm{NPI}, \mathrm{ADLS}$ \\
\hline Vercelletto, M. [19] & 49 & $\mathrm{CIBIC}+$ & MMSE, DRS & $\mathrm{NPI}, \mathrm{FBI}, \mathrm{DAD}, \mathrm{ZBI}$ \\
\hline Boxer, A.L. [7] & 81 & $\mathrm{CGI}-\mathrm{C}$ & $\begin{array}{l}\text { CVLT, fluency, BNT, Trail Making test, } \\
\text { Digit Backwards, Digit symbol }\end{array}$ & NPI \\
\hline Jesso, S. [26] & 20 & --- & $\begin{array}{c}\text { Emotion recognition, emotion processing, } \\
\text { Theory of Mind task }\end{array}$ & $\mathrm{NPI}, \mathrm{FBI}$ \\
\hline
\end{tabular}

$A D L S$, alzheimer's disease cooperative study-activities of daily living scale; $B E H A V-A D$, behavioral pathology in alzheimer's disease rating scale; $B N T$, Boston naming test; $C B I$, Cambridge behavioral inventory; CGI-C, clinical global impression of change; CGI-I, clinical global impression of improvement; CGI-S, clinical global impression of severity; $C I B I C+$, clinician's interview-based impression of change plus caregiver input; CIRS, clinical insight rating scale; CSDD, cornell scale for depression in dementia; CVLT, California verbal learning test; $D A D$, disability assessment for dementia; $D R S$, dementia rating scale, $F B I$, frontal behavioral inventory; MMSE, mini mental status exam; NART, National test of adult reading; NPI, neuropsychiatric inventory; RBANS, repeatable battery for the assessment of neuropsychological status; WAB, Western Aphasia battery; $Z B I$, Zarit burden inventory.

*(immediate and delayed pattern recognition, spatial recognition, spatial span, spatial working memory, visual discrimination learning/attentional set shifting, decision-making "gamble," and paired associates learning).

**(pattern recognition memory, spatial recognition memory, spatial span, spatial working memory, and intradimensional (ID)/extradimensional (ED) attentional-set shifting, and Tower of London test of spatial planning).

multiple behavioral endpoints. The Neuropsychiatric Inventory (NPI) [14] was the most frequently employed, appearing in eight of nine studies. The extent to which findings of behavioral improvement across trials is related to greater uniformity in assessment approaches remains unclear, though greater consistency would minimize superfluous variance related to methods.

\section{Limitations of the existing literature}

Although there are myriad reasons why a trial could fail, one possible explanation for the lack of significant findings may relate to the endpoint selection. Within the field of neuropsychology, there is a relative lack of consensus regarding operationalization of cognitive constructs and selection of measures to quantify those constructs, with many different tests currently being used in research and clinical applications see [30,31] for review. The result is that the same construct has been defined and measured in multiple ways, using different tests that do not necessarily overlap. One immediate consequence of this variability is the introduction of unique method variance to outcomes research due to the use of tests with varying psychometric properties (e.g., standard error of measurement, reliability), which potentially masks treatment effects, inflates Type I and Type II measurement error, and hinders largescale aggregation of data for meta-analytic study. The lack of evidence for cognitive improvement in a RCT may also be due to selection of insensitive measures. In the early phases of the disease, the changes in cognition may be so subtle that the measures employed lacked adequate sensitivity to small magnitudes of change.
One approach to enhancing uniformity and facilitating use of appropriate measures is to promote convergence among investigators toward common methods and data elements (e.g., NIH Toolbox, The Cognitive Atlas, Patient Reported Outcome Measurement Information System [PROMIS]), particularly for those tools used in clinical trials. Although the trial performance characteristics are unknown, the Uniform Data Set (UDS) for FTLD is one example of a brief cognitive battery that has been developed and successfully deployed to create uniformity among assessments at Alzheimer's Disease Centers [32]. The NIH EXAMINER is a battery targeting brief assessment of executive functioning and social cognition, specifically for use in clinical trials. It has shown promise for the assessment of executive functions $[33,34]$ and if acceptable performance characteristics in clinical trials can be demonstrated, its adoption would facilitate measurement standardization.

\section{What makes a good endpoint?}

During the planning phase of a controlled trial, selection of appropriate measures is crucial, and there are multiple factors to consider in addition to FDA or EMA requirements. Given the potential for small effect sizes, measures must be able to identify small incremental changes over time by employing a metric that is fine enough to detect such changes. For example, using a measure with a binary metric (e.g., "normal" vs. "impaired") may be too coarse and risk missing more subtle degrees of change. It is also imperative that the measures provide adequate coverage of the constructs or behaviors of interest, sampling over 
the entire range of possible outcomes in order to minimize limitations imposed by statistical distributions (i.e., ceiling and floor effects). Using measures that have a level of difficulty so low that baseline assessments result in a preponderance of scores falling at or near the ceiling is inappropriate, as such a distribution of scores allows for change in only one direction (i.e., decline). Measures also cannot be so difficult that the distribution of obtained scores is skewed towards the floor, for similar reasons. Additionally, by selecting measures with inadequate coverage, or too small a range of possible measurements, the risk of generating skewed data is increased.

Outcome measures should also be suitable for repeat administration, yet relatively robust to practice effects to ensure that observed changes reflect true signal variance and not residual effects due to repeated measurement (i.e., practice effects) or poor reliability. The inherent nature of a randomized controlled trial results in multiple assessments over the course of the trial and there are several methods to help account for practice effects. Some measures, however, are more vulnerable than others. For example, use of the Wisconsin Card Sorting Test [35], while useful in some clinical contexts, is particularly susceptible to practice effects $[36,37]$ and is thus inappropriate for use in clinical trials as a primary endpoint. While many measures employ alternate forms, which can be beneficial, they are not immune to practice effects due procedural familiarity with the assessment process (e.g., knowing that a presented word list or visual display is likely subject to later recall). In addition to careful selection of measures, practice effects should be accounted for in the methodological design and statistical analyses. The significance of practice effects cannot be overstated, as they can significantly inflate Type I error rates by masking decline. Using an unreliable test leads to similar concerns.

In order to increase the potential for widespread adoption of an endpoint, the trial measures should also be readily available and easily accessible. Using measures that are difficult or expensive to obtain, and complicated and lengthy to administer will limit implementation. Identifying a small set of measures to be employed across FTD clinical trials will facilitate synthesis of results, meta-analysis and critical review, fostering development of a stronger evidence-base. With the increasing prevalence of multinational trials, using endpoints that have been translated and standardized across multiple languages is also beneficial where possible. The Addenbrooke Cognitive Examination, Revised (ACER) [38] and Montreal Cognitive Assessment (MoCA) [39] for example, have each been translated into several different languages facilitating international use.

\section{Global measures}

As with RCTs for AD, clinical trials in FTD should give strong consideration for use of a combined measure that quantifies cognitive, behavioral and functional status in a single metric in order to increase sensitivity to change, particularly in the early phases of the disease. The Clinical Dementia Rating - Sum of Box Scores (CDR-SOB) is one such example that has been used in AD trials and an extension of the CDR adding two domains specific to FTD has also been developed (FTD-CDR), which includes ratings for Language as well as Behavior, Comportment and Personality [40]. The FTD-CDR has demonstrated an association with degree of hypometabolism on fluorodeoxyglucose positron emissions tomography (FDG-PET) studies [41] and demonstrated sensitivity to change in a mock clinical trial [40]. Similarly, the Clinician Global Impressions scales should also be considered, as they have already been implemented in several trials and have documented sensitivity to change [7]. The ACE-R, which incorporates the MMSE as well as further assessment of attention, memory, verbal fluency, language and visuospatial function has also shown sensitivity to change in bvFTD [42].

The CIBIC [4] is another example of a viable measure which incorporates a caregiver interview (CIBIC+). The CIBIC + utilizes Likert scales for disease severity and changes based on observation and written accounts summarizing semi-structured interviews evaluating behavior, cognition, and function and has demonstrated sensitivity to change in placebo groups [19]. Appropriate use of the FTD-CDR and CIBIC + relies on the expertise of the examiner and, as with any interview-based measure generating ratings on subjective input, being mindful of the quality and reliability of informant data is important. Training, clinical trial site quality, turnover of raters, and other operational details impact the quality of data collected and must be supervised in a RCT.

The sample size required to show a drug-placebo difference in a clinical trial depends on the observed rate of change, the standard deviation of the measure, and the effect size of the agent. The FTD-CDR changes by approximately 3.5 pointe per year. Anticipating a small effect size of disease-modifying agents (e.g., 25\% showing), Knopman et al. (2008) estimated a sample size of 251 for an alpha of 0.05 and power of $80 \%$ (for a two arm trial). Composite scores based on multiple assessments of executive function or language function shows greater annual change and smaller sample sizes to demonstrate a drug benefit $[40,43]$. Recruiting the required number of patients will require multiple sites and diligent effort.

\section{Individual measures}

For many reasons, a brief screening measure may be a tempting endpoint. However, selection of an appropriate measure becomes even more critical when using a brief measure with fewer items, as a smaller item pool negatively influences reliability and stability of estimates. The 
MMSE for example, has been used extensively as a screening tool and secondary outcome in clinical trials in $\mathrm{AD}$, and has been one of the most frequent cognitive endpoints used in FTD trials to date. However, the MMSE lacks executive function measures and relies heavily on changes in memory to generate an abnormal score, which may not capture the cognitive changes in FTD. Not only does the MMSE have inadequate coverage of the target domains, it is also highly prone to ceiling effects and utilizes a relatively coarse metric, thus seriously limiting its appropriateness in a clinical trial setting. The MoCA may be a better alternative, showing increased sensitivity to cognitive impairment over the MMSE [44-46] while retaining a similar level of simplicity in both scoring and administration. The MoCA has demonstrated sensitivity to change over time in a dementia population [47]. The MoCA provides greater assessment of a broader range of cognitive abilities, including executive functioning and may capture critical elements of the FTD syndrome. The MoCA has been validated in multiple languages and has alternate forms available [48].

Targeted assessment of cognition, particularly language and executive functioning, may be warranted depending on the nature of the trial and study population. Assessment of language functioning is key for trials focusing on the language-predominant subtypes of FTD (i.e., semantic dementia, progressive non-fluent aphasia). Reliable assessment can be difficult due to the importance of qualitative changes (e.g., rate, prosody, latency) in language not readily captured by traditional language measures. In some instances it may be beneficial to generate audio recordings of participants to allow for multiple ratings of speech and language quality; however, quantitative metrics are needed. Two commonly employed clinical measures of expressive and receptive language that allow for flexibility in their administration and targeting of specific language components are the Western Aphasia Battery WAB; [49] and the Boston Diagnostic Aphasia Examination BDAE; [50]. The ACE has also demonstrated sensitivity to language impairments and change over time in PNFA and SD [51] and the Boston Naming Test BNT; [52] has also been widely used. Development and validation of novel assessment approaches and tools for measuring language may be required and advancements in voice recognition software and integration of technology may prove useful [53].

Given the known changes in frontal systems functioning, measuring executive functions should be an integral component of clinical trials in FTD. Trials in AD have previously employed trail making tests, fluency estimates, and response inhibition, though many of these tests are performance-based and vulnerable to practice effects, which will need to be prospectively addressed in the experimental design and data analysis. The Executive
Interview (EXIT-25) is a brief cognitive screen that emphasizes executive function, and has been used in clinical trials in this population [7,54]. A similar executive screening measure, the Frontal Assessment Battery (FAB) [55], has been used with some suggestion of superiority to the EXIT-25 [56]. The NIH EXAMINER [33] is another battery developed explicitly as a brief, efficient method of assessing executive functions for use in clinical trials, however, multisite assessment and independent validation of this approach are needed.

Including assessment of memory is also important, though perhaps less so in comparison to AD trials where memory impairment is a primary symptom. If memory is to be quantified, selection of appropriate endpoints will require careful consideration, as traditional indices of memory functioning may be problematic as markers of cognitive change. Delayed free-recall scores are highly susceptible to floor effects, while recognition scores are limited by ceiling effects, particularly early in the phase of disease when changes are more likely to be very subtle. Alternatively, learning acquisition (i.e., learning over trials) as a marker of immediate recall, recall-recognition contrast measures, or recognition discriminability (i.e., hits vs. false-positives) may be better outcomes for assessing memory that are readily generated by many verbal and nonverbal list-learning tasks (e.g., California Verbal Learning Test, 2nd Ed.; [57]; Hopkins Verbal Learning Test; [58]).

\section{Composite measures}

A potential risk of using multiple individual measures as the primary or secondary cognitive endpoints is the challenge of multiplicity, from which it may be difficult to derive meaningful change. Composite scores potentially address this issue by aggregating results from individual measures into a single cognitive index; however, use of composites must be theoretically justified. Creating a composite score via statistical data reduction methods (e. g., principal components analysis, factor analysis) may not be appropriate as it relies on a posteriori knowledge and capitalizes upon unique variances within the study sample that may limit generalization of the composites to other samples. A variant on generating a composite score is use of a standardized battery that generates both individual domain scores as well as a global index, which can be implemented across multiple sites using a common normative reference. In addition to the NIH EXAMINER, the cognitive subscale of the ADAS-Cog is an example of a composite battery that has been widely employed in AD drug trials. As with the MMSE, however, the ADAS-Cog targets the domains of memory and language and, in order to be appropriate for use in FTD trials, the expanded version, which includes additional assessment of executive functions, should be used [59]. Experience with this 
Table 2 Review of potential endpoints for consideration

\begin{tabular}{|c|c|c|c|}
\hline Domain & Test example & Strengths & Limitations \\
\hline \multirow[t]{3}{*}{ Global } & $\begin{array}{l}\text { Clinician Interview Based } \\
\text { Impression of Change } \\
\text { (with caregiver interview) }\end{array}$ & $\begin{array}{l}\text { Evaluates behavior, cognition and functioning; } \\
\text { previously used in clinical trials; demonstrated } \\
\text { sensitivity to change }\end{array}$ & Relies on subjective data from caregivers \\
\hline & Clinical Dementia Rating & $\begin{array}{l}\text { FTD-Specific version available; sensitive to change; } \\
\text { association with biomarkers }\end{array}$ & $\begin{array}{l}\text { Reliance on subjective data; lengthy } \\
\text { to administer; coarse metric }\end{array}$ \\
\hline & Clinical Global Impressions & $\begin{array}{l}\text { Widely used in existing trials in FTD; } \\
\text { sensitive to change; individual subscales available }\end{array}$ & Reliance on subjective data \\
\hline \multirow[t]{5}{*}{ Composite } & $\begin{array}{l}\text { Montreal Cognitive } \\
\text { Assessment }\end{array}$ & $\begin{array}{l}\text { Brief screen; sensitive to change; multicultural; } \\
\text { alternate forms; freely available }\end{array}$ & $\begin{array}{l}\text { Limited use in clinical trials; insufficient coverage } \\
\text { of cognitive domains; potential for ceiling effects }\end{array}$ \\
\hline & $\begin{array}{l}\text { Repeatable Battery for } \\
\text { the Assessment of } \\
\text { Neuropsychological Status }\end{array}$ & Multi-domain assessment; alternate forms available & Inadequate coverage of executive functioning \\
\hline & $\begin{array}{l}\text { Dementia Rating Scale, } \\
\text { 2nd Ed. }\end{array}$ & $\begin{array}{l}\text { Multi-domain assessment sensitive to presence } \\
\text { of dementia; previously used in clinical trials }\end{array}$ & $\begin{array}{l}\text { Limited assessment of executive functioning; } \\
\text { no alternate form }\end{array}$ \\
\hline & EXAMINER & $\begin{array}{l}\text { Developed with FTD in mind; intended for clinical } \\
\text { trials; customizable; specific to executive functioning; } \\
\text { measures social cognition and behavior }\end{array}$ & Actual trial performance is to be determined \\
\hline & $\begin{array}{l}\text { Neuropsychological } \\
\text { Test Battery }\end{array}$ & Proven trial performance; sensitive to change & $\begin{array}{l}\text { Relies heavily on memory functioning; } \\
\text { no alternate forms }\end{array}$ \\
\hline \multirow[t]{5}{*}{ Executive } & Trail Making Test & $\begin{array}{l}\text { Previously used in clinical trials; extensive } \\
\text { normative data; widely used }\end{array}$ & $\begin{array}{l}\text { Limited sensitivity to change in previous trials; } \\
\text { prone to floor effects }\end{array}$ \\
\hline & Stroop Test & $\begin{array}{l}\text { Multiple variants available; extensive normative data; } \\
\text { previously used in clinical trials; relatively immune to } \\
\text { ceiling effects }\end{array}$ & $\begin{array}{l}\text { Sensitive to practice effects; interference } \\
\text { conditions may be prone to floor effects }\end{array}$ \\
\hline & EXIT-25 & Previously used in FTD trials & $\begin{array}{l}\text { Longer and more complicated } \\
\text { administration than comparable alternatives }\end{array}$ \\
\hline & Frontal Assessment Battery & $\begin{array}{l}\text { Brief, simple administration; sensitive to } \\
\text { change; multiple language versions }\end{array}$ & No alternate forms \\
\hline & Clock Drawing & $\begin{array}{l}\text { Sensitive to executive dysfunction; simple } \\
\text { and brief administration; many variants available }\end{array}$ & $\begin{array}{l}\text { Sensitivity and specificity vary as a function } \\
\text { of version used. }\end{array}$ \\
\hline \multirow[t]{4}{*}{ Language } & $\begin{array}{l}\text { Boston Diagnostic } \\
\text { Aphasia Examination }\end{array}$ & $\begin{array}{l}\text { Sensitive to expressive and receptive } \\
\text { language impairments; }\end{array}$ & $\begin{array}{l}\text { Limited use in clinical trials; limited sensitivity } \\
\text { to speech abnormalities; no alternate forms; } \\
\text { prone to ceiling effects }\end{array}$ \\
\hline & Western Aphasia Battery & $\begin{array}{l}\text { Sensitive to expressive language impairments; } \\
\text { previous use in clinical trials }\end{array}$ & $\begin{array}{l}\text { limited sensitivity to speech abnormalities; } \\
\text { no alternate forms; prone to ceiling effects }\end{array}$ \\
\hline & $\begin{array}{l}\text { Controlled Oral Word } \\
\text { Association Test }\end{array}$ & Previously used in trials; sensitive to change & $\begin{array}{l}\text { Only one well-validated alternate form; } \\
\text { culturally limited }\end{array}$ \\
\hline & Boston Naming Test & $\begin{array}{l}\text { Widely used; extensive normative data; } \\
\text { some use in trials }\end{array}$ & $\begin{array}{l}\text { Non-normal distribution of scores; } \\
\text { no alternate forms; culturally limited }\end{array}$ \\
\hline \multirow[t]{2}{*}{ Memory } & $\begin{array}{l}\text { California Verbal } \\
\text { Learning Test, 2nd Ed. }\end{array}$ & $\begin{array}{l}\text { Provides multiple estimates of memory (including } \\
\text { learning) and insight into executive functioning }\end{array}$ & $\begin{array}{l}\text { Only one alternate form; lengthy to administer; } \\
\text { Recognition trials vulnerable to ceiling effects }\end{array}$ \\
\hline & $\begin{array}{l}\text { Rey Auditory Verbal } \\
\text { Learning Test }\end{array}$ & $\begin{array}{l}\text { Previously used in clinical trials; provides estimates } \\
\text { of learning, recall and recognition }\end{array}$ & $\begin{array}{l}\text { Recognition trials vulnerable to ceiling effects; } \\
\text { recall trials vulnerable to floor effects }\end{array}$ \\
\hline \multirow[t]{2}{*}{$\begin{array}{l}\text { Visuospatial } \\
\text { Functioning }\end{array}$} & Judgment of Line Orientation & $\begin{array}{l}\text { Relatively free from practice effects; minimal } \\
\text { demand on motor and language }\end{array}$ & $\begin{array}{l}\text { Vulnerable to ceiling effects; } \\
\text { can be lengthy administration }\end{array}$ \\
\hline & Figure Copy tests & $\begin{array}{l}\text { Insights into perception, organization and } \\
\text { executive functioning; multiple forms }\end{array}$ & $\begin{array}{l}\text { Confounded by motor impairment; } \\
\text { scoring can be complex }\end{array}$ \\
\hline \multirow[t]{3}{*}{ Behavior } & $\begin{array}{l}\text { Neuropsychiatric } \\
\text { Inventory }\end{array}$ & Widely used in clinical trials; sensitive to change & $\begin{array}{l}\text { Not specific to behavioral changes associated } \\
\text { with FTD; large standard variations; Improvements } \\
\text { may be related to increasing apathy }\end{array}$ \\
\hline & Frontal Behavior Inventory & Sensitive to change; employed in existing trials & Improvements may be related to increasing apathy \\
\hline & $\begin{array}{l}\text { Frontal Systems } \\
\text { Behavior Examination }\end{array}$ & $\begin{array}{l}\text { Allows for intra-individual comparison; } \\
\text { quantification of apathy }\end{array}$ & Relies on reliable informant \\
\hline
\end{tabular}


expanded version in FTLD is limited. The DRS and RBANS are two similar, brief cognitive batteries that have been used in clinical trials, however, neither provides adequate coverage of the executive domain and would need to be supplemented with additional measures. Another example of a composite measure designed and implemented in clinical trials for $\mathrm{AD}$ is the Neuropsychological Test Battery (NTB) [60]. The advantage of the NTB over other composites used in $\mathrm{AD}$ trials is the added focus on executive functioning and with known performance characteristics in clinical trials [61], it may be a viable endpoint for use in FTD trials.

\section{Behavioral measures}

For trials targeting bvFTD, reliable assessment of behavioral functioning is an essential component. The NPI and Frontal Behavioral Inventory (FBI) $[62,63]$ have both been shown to reliably differentiate between FTD subtypes at baseline [40] and have shown sensitivity to change over time [26]. In some circumstances, these measures may need to be supplemented with additional behavioral assessment tools due to their emphasis on more "positive" behavioral disturbances (e.g., agitation, irritability, disinhibition) over "negative" behaviors (e.g., apathy, indifference), which are among the core features of FTD. Including measures that capture more of these negative behaviors is recommended in order to ensure that the spectrum of behavioral disturbances is captured. The Frontal Systems Behavior Scale FrSBE; [64-66] is another option for quantification of behavioral disturbances that yields separate indexes for apathy, disinhibition and executive dysfunction. In addition to assessing apathy, the FrSBe also allows for intra-individual comparisons. A significant limitation with most, if not all, measures of behavioral disturbance is that they rely on the accuracy of caregiver reports. Integrating clinician ratings of behavior can be beneficial, however, these are restricted to observable behaviors that may not manifest in clinic and are heavily influenced by caregiver reports. Development of behavioral assessment methods that allow for greater objectivity and validation of caregiver reports may be particularly beneficial.

\section{Conclusions}

Although not intended to be a comprehensive, nor exhaustive listing, Table 2, provides an overview of tools that could be considered for FTD trials, describing their roles, as well as potential strengths and limitations. Choosing appropriate endpoints for use in clinical trials is a complex and difficult decision that has direct implications on potential for success. For trials focusing on FTD, a principal challenge in choosing the optimal outcome measures will depend on how heterogeneous the targeted FTD sample is likely to be in a given trial. In studies focusing on one primary subtype (e.g., bvFTD), a primary outcome measure targeting that groups' main symptom combined with a global or functional coprimary may be appropriate. Studies aimed at more heterogeneous samples on the other hand, may require outcomes surveying a broader range of functioning in order to generate meaningful results. Use of readily available measures that provide sufficient coverage of the targeted domain while retaining an adequate sensitivity to change is critical in order to maximize chances for beneficial outcomes. Development and application of appropriate trial outcomes is critically important to success in development of necessary treatments for FTD patients.

\section{Competing interests}

Dr. Cummings owns the copyright of the Neuropsychiatric Inventory. Drs. Miller, Banks and Leger declare that they have no competing interests.

\section{Authors' contributions}

All authors contributed to the preparation of this manuscript and have provided final approval of the version to be published.

Received: 21 March 2014 Accepted: 1 June 2014

Published: 5 June 2014

\section{References}

1. Ratnavalli E, Brayne C, Dawson K, Hodges JR: The prevalence of frontotemporal dementia. Neurology 2002, 58(11):1615-1621.

2. Mackenzie IRA, Neumann M, Baborie A, Sampathu DM, Plessis DD, Jaros E, Perry RH, Trojanowski JQ, Mann DMA, Lee VMY: A harmonized classification system for FTLD-TDP pathology. Acta Neuropathol 2011, 122(1):111-113.

3. Mackenzie IRA, Neumann M, Bigio EH, Cairns NJ, Alafuzoff I, Kril J, Kovacs GG, Ghetti B, Halliday G, Holm IE, Ince PG, Kamphorst W, Revesz T, Rozemuller AJM, Kumar-Singh S, Akiyama H, Baborie A, Spina S, Dickson DW, Trojanowski JQ, Mann DMA: Nomenclature and nosology for neuropathologic subtypes of frontotemporal lobar degeneration: an update. Acta Neuropathol 2010, 119(1):1-4.

4. Knopman D, Knapp MJ, Gracon SI, Davis CS: The Clinician Interview-Based Impression $(\mathrm{ClBI})$ - a clinician global change rating-scale in Alzheimer's disease. Neurology 1994, 44(12):2315-2321

5. Weintraub S, Mesulam M: With or without FUS, it is the anatomy that dictates the dementia phenotype. Brain 2009, 132:2906-2908.

6. Gorno-Tempini ML, Hillis AE, Weintraub S, Kertesz A, Mendez M, Cappa SF, Ogar JM, Rohrer JD, Black S, Boeve BF, Manes F, Dronkers NF, Vandenberghe R, Rascovsky K, Patterson K, Miller BL, Knopman DS, Hodges JR, Mesulam MM, Grossman M: Classification of primary progressive aphasia and its variants. Neurology 2011, 76(11):1006-1014.

7. Boxer AL, Knopman DS, Kaufer DI, Grossman M, Onyike C, Graf-Radford N, Mendez M, Kerwin D, Lerner A, Wu CK, Koestler M, Shapira J, Sullivan K, Klepac K, Lipowski K, Ullah J, Fields S, Kramer JH, Merrilees J, Neuhaus J, Mesulam MM, Miller BL: Memantine in patients with frontotemporal lobar degeneration: a multicentre, randomised, double-blind, placebo-controlled trial. Lancet Neurol 2013, 12(2):149-156.

8. Leber P: Guidelines for the Clinical Evaluation of Antidementia Drugs. Rockville, MD: U.S.F.a.D. Administration, 1990, U.S. Food and Drug Administration; 1990.

9. Schneider LS, Olin JT, Doody RS, Clark CM, Morris JC, Reisberg B, Schmitt FA, Grundman M, Thomas RG, Ferris SH: Validity and reliability of the Alzheimer's Disease cooperative study - Clinical global impression of change. Alzheimer Dis Assoc Disord 1997, 11:S22-S32.

10. Williams MM, Storandt M, Roe CM, Morris JC: Progression of Alzheimer's disease as measured by Clinical Dementia Rating Sum of Boxes scores. Alzheimers Dement 2013, 9(1 Suppl):S39-S44.

11. Galasko D, Bennett D, Sano M, Ernesto C, Thomas R, Grundman M, Ferris S: An inventory to assess activities of daily living for clinical trials in Alzheimer's disease. Alzheimer Dis Assoc Disord 1997, 11:S33-S39. 
12. Gelinas I, Gauthier L, McIntyre M, Gauthier S: Development of a functional measure for persons with Alzheimer's disease: the disability assessment for dementia. Am J Occupat Ther 1999, 53(5):471-481.

13. Rosen WG, Mohs RC, Davis KL: A new rating scale for Alzheimer's disease. Am J Psychiatry 1984, 141(11):1356-1364.

14. Cummings JL, Mega M, Gray K, Rosenbergthompson S, Carusi DA, Gornbein $\mathrm{J}$ : The neuropsychiatric inventory - comprehensive assessment of psychopathology in dementia. Neurology 1994, 44(12):2308-2314.

15. Wimo A, Winblad B, Stoffler A, Wirth Y, Mobius HJ: Resource utilisation and cost analysis of memantine in patients with moderate to severe Alzheimer's disease. Pharmacoeconomics 2003, 21(5):327-340.

16. Hu WT, Trojanowski JQ, Shaw LM: Biomarkers in frontotemporal lobar degenerations-progress and challenges. Prog Neurobiol 2011, 95(4):636-648.

17. Cummings J, Zhong K: Biomarker-driven therapeutic management of alzheimer's disease: establishing the foundations. Clin Pharmacol Ther 2014, 95(1):67-77.

18. Nardell M, Tampi RR: Pharmacological treatments for frontotemporal dementias: a systematic review of randomized controlled trials. Am J Alzheimers Dis Other Demen 2014, 29(2):123-132.

19. Vercelletto M, Boutoleau-Bretonniere C, Volteau C, Puel M, Auriacombe S, Sarazin M, Michel BF, Couratier P, Thomas-Anterion C, Verpillat P, Gabelle A, Golfier V, Cerato E, Lacomblez L: Memantine in behavioral variant frontotemporal dementia: negative results. J Alzheimers Dis 2011, 23(4):749-759.

20. Moretti R, Torre P, Antonello RM, Cazzato G, Bava A: Frontotemporal dementia: Paroxetine as a possible treatment of behavior symptoms - a randomized, controlled, open 14-month study. Eur Neurol 2003, 49(1):13-19.

21. Deakin JB, Rahman S, Nestor PJ, Hodges JR, Sahakian BJ: Paroxetine does not improve symptoms and impairs cognition in frontotemporal dementia: a double-blind randomized controlled trial. Psychopharmacology (Berl) 2004, 172(4):400-408.

22. Lebert F, Stekke W, Hasenbroekx C, Pasquier F: Frontotemporal dementia: a randomised, controlled trial with trazodone. Dement Geriatr Cogn Disord 2004, 17(4):355-359.

23. Rahman S, Robbins TW, Hodges JR, Mehta MA, Nestor PJ, Clark L, Sahakian BJ: Methylphenidate ('Ritalin') can ameliorate abnormal risk-taking behavior in the frontal variant of frontotemporal dementia. Neuropsychopharmacology 2006, 31(3):651-658.

24. Huey ED, Putnam KT, Grafman J: A systematic review of neurotransmitter deficits and treatments in frontotemporal dementia. Neurology 2006, 66(1):17-22.

25. Kertesz A, Morlog D, Light M, Blair M, Davidson W, Jesso S, Brashear R: Galantamine in frontotemporal dementia and primary progressive aphasia. Dement Geriatr Cogn Disord 2008, 25(2):178-185

26. Jesso S, Morlog D, Ross S, Pell MD, Pasternak SH, Mitchell DGV, Kertesz A Finger EC: The effects of oxytocin on social cognition and behaviour in frontotemporal dementia. Brain 2011, 134(Pt 9):2493-2501.

27. Mattis S: Dementia Rating Scale. 2nd edition. Lutz, FL: Psychological Assessment Resources, Inc; 2002.

28. Randolph C: Repeatable Battery for the Assessment of Neuropsychological Status. San Antonio, TX: Psychological Corporation; 1998.

29. Folstein MF, Folstein SE, McHugh PR: Mini-mental state. A practical method for grading the cognitive state of patients for the clinician. J Psychiatr Res 1975, 12(3):189-198.

30. Lezak MD, Howieson DB, Loring DW: Neuropsychological Asessment. 4th edition. New York: Oxford University Press; 2004.

31. Straus E, Sherman EMS, Spreen O: A compendium of neuropsychological tests: Administration, norms, and commentary. 3rd edition. New York: Oxford University Press; 2006.

32. Weintraub S, Salmon D, Mercaldo N, Ferris S, Graff-Radford NR, Chui H, Cummings J, DeCarli C, Foster NL, Galasko D, Peskind E, Dietrich W, Beekly DL, Kukull WA, Morris JC: The Alzheimer's Disease Centers' Uniform Data Set (UDS): the neuropsychologic test battery. Alzheimer Dis Assoc Disord 2009, 23(2):91-101.

33. Kramer JH, Mungas D, Possin KL, Rankin KP, Boxer AL, Rosen $H J$, Bostrom $A$ Sinha L, Berhel A, Widmeyer M: NIH EXAMINER: conceptualization and development of an executive function battery. J Int Neuropsychol Soc 2014, 20(1):11-19.

34. Possin KL, LaMarre AK, Wood KA, Mungas DM, Kramer JH: Ecological validity and neuroanatomical correlates of the NIH EXAMINER executive composite score. J Int Neuropsychol Soc 2014, 20(1):20-28.
35. Heaton SK, Chelune GJ, Talley JL, Kay GG, Curtiss G: Wisconsin Card Sorting Test Manual: Revised and Expanded. Odessa, FL: Psychological Assessment Resources, Inc; 1993.

36. Basso MR, Bornstein RA, Lang JM: Practice effects on commonly used measures of executive function across twelve months. Clin Neuropsychol 1999, 13(3):283-292.

37. Basso MR, Lowery N, Ghormley C, Bornstein RA: Practice effects on the Wisconsin Card Sorting Test-64 Card version across 12 months. Clin Neuropsychol 2001, 15(4):471-478.

38. Mioshi E, Dawson K, Mitchell J, Arnold R, Hodges JR: The Addenbrooke's Cognitive Examination Revised (ACE-R): a brief cognitive test battery for dementia screening. Int J Geriatr Psychiatry 2006, 21(11):1078-1085.

39. Nasreddine ZS, Phillips NA, Bedirian V, Charbonneau S, Whitehead V, Collin I, Cummings $\mathrm{J}$, Chertkow $\mathrm{H}$ : The montreal cognitive assessment, MoCA: $\mathrm{A}$ brief screening tool for mild cognitive impairment. J Am Geriatr Soc 2005, 53(4):695-699.

40. Knopman D, Kramer J, Boeve B, Caselli R, Graff-Radford N, Mendez M, Miller $B$, Mercaldo N: Development of methodology for conducting clinical trials in frontotemporal lobar degeneration. Brain 2008, 131(Pt 11):2957-2968.

41. Borroni B, Agosti C, Premi E, Cerini C, Cosseddu M, Paghera B, Bellelli G, Padovani A: The FTLD-modified Clinical Dementia Rating scale is a reliable tool for defining disease severity in Frontotemporal Lobar Degeneration: evidence from a brain SPECT study. Eur J Neurol 2010, 17(5):703-707

42. Kipps CM, Nestor PJ, Dawson CE, Mitchell J, Hodges JR: Measuring progression in frontotemporal dementia: implications for therapeutic interventions. Neurology 2008, 70(22):2046-2052.

43. Knopman DS, Jack CR Jr, Kramer JH, Boeve BF, Caselli RJ, Graff-Radford NR, Mendez MF, Miller BL, Mercaldo ND: Brain and ventricular volumetric changes in frontotemporal lobar degeneration over 1 year. Neurology 2009, 72(21):1843-1849.

44. Freitas S, Simoes MR, Alves L, Duro D, Santana I: Montreal Cognitive Assessment (MoCA): validation study for frontotemporal dementia. J Geriatr Psychiatry Neurol 2012, 25(3):146-154.

45. Hoops S, Nazem S, Siderowf AD, Duda JE, Xie SX, Stern MB, Weintraub D: Validity of the MoCA and MMSE in the detection of $\mathrm{MCl}$ and dementia in Parkinson disease. Neurology 2009, 73(21):1738-1745.

46. Larner AJ: Screening utility of the Montreal Cognitive Assessment (MoCA): in place of - or as well as - the MMSE? Int Psychogeriatr 2012, 24(3):391-396

47. Freitas S, Simoes MR, Alves L, Santana I: Montreal cognitive assessment: validation study for mild cognitive impairment and Alzheimer disease. Alzheimer Dis Assoc Disord 2013, 27(1):37-43.

48. Costa AS, Fimm B, Friesen P, Soundjock H, Rottschy C, Gross T, Eitner F Reich A, Schulz JB, Nasreddine ZS, Reetz K: Alternate-form reliability of the montreal cognitive assessment screening test in a clinical setting Dement Geriatr Cogn Disord 2012, 33(6):379-384.

49. Kertesz A: Western Aphasia Battery. San Antonio, TX: Psychological Corporation; 2007.

50. Goodglass H, Kaplan E: Assessment of Aphasia and Related Disorders. Philadelphia, PA: Lea \& Febinger; 1972

51. Leyton CE, Hornberger M, Mioshi E, Hodges JR: Application of Addenbrooke's cognitive examination to diagnosis and monitoring of progressive primary aphasia. Dement Geriatr Cogn Disord 2010, 29(6):504-509.

52. Goodglass H, Kaplan E, Weintraub S: Boston Naming Test. Philadelphia, PA: Lea \& Febinger; 1983

53. Pakhomov SV, Smith GE, Marino S, Birnbaum A, Graff-Radford N, Caselli R, Boeve B, Knopman DS: A computerized technique to assess language use patterns in patients with frontotemporal dementia. J Neurolinguistics 2010, 23(2):127-144.

54. Boxer AL, Lipton AM, Womack K, Merrilees J, Neuhaus J, Pavlic D, Gandhi A Red D, Martin-Cook K, Svetlik D, Miller BL: An open-label study of memantine treatment in 3 subtypes of frontotemporal lobar degeneration. Alzheimer Dis Assoc Disord 2009, 23(3):211-217.

55. Dubois B, Slachevsky A, Litvan I, Pillon B: The FAB: a Frontal Assessment Battery at bedside. Neurology 2000, 55(11):1621-1626.

56. Moorhouse P, Gorman M, Rockwood K: Comparison of EXIT-25 and the frontal assessment battery for evaluation of executive dysfunction in patients attending a memory clinic. Dement Geriatr Cogn Disord 2009, 27(5):424-428 
57. Delis DC, Kramer JH, Kaplan E, Ober BA: California Verbal Learning Test. 2nd edition. San Antonio, TX: Psychological Corporation; 2000.

58. Brandt J, Benedict RHB: Hopkins Verbal Learning Test-Revised. Lutz, FL: Psychological Assessment Resources, Inc; 2001.

59. Mohs RC, Knopman D, Petersen RC, Ferris SH, Ernesto C, Grundman M, Sano M, Bieliauskas L, Geldmacher D, Clark C, Thal L: Development of cognitive instruments for use in clinical trials of antidementia drugs: additions to the Alzheimer's Disease Assessment Scale that broaden its scope. The Alzheimer's Disease Cooperative Study. Alzheimer Dis Assoc Disord 1997, 11(Suppl 2):S13-S21.

60. Harrison J, Psychol C, Minassian SL, Jenkins L, Black RS, Koller M, Grundman M: A neuropsychological test battery for use in Alzheimer disease clinical trials. Arch Neurol 2007, 64(9):1323-1329.

61. Karin A, Hannesdottir K, Jaeger J, Annas P, Segerdahl M, Karlsson P, Sjogren $\mathrm{N}$, von Rosen T, Miller F: Psychometric evaluation of ADAS-Cog and NTB for measuring drug response. Acta Neurol Scand 2014, 129(2):114-122.

62. Kertesz A, Davidson W, Fox H: Frontal behavioral inventory: Diagnostic criteria for frontal lobe dementia. Can J Neurol Sci 1997, 24(1):29-36.

63. Kertesz A, Nadkarni N, Davidson W, Thomas AW: The Frontal Behavioral Inventory in the differential diagnosis of frontotemporal dementia. $J$ Int Neuropsychol Soc 2000, 6(4):460-468.

64. Carvalho JO, Ready RE, Malloy P, Grace J: Confirmatory factor analysis of the Frontal Systems Behavior Scale (FrSBe). Assessment 2013, 20(5):632-641.

65. Grace J, Stout JC, Malloy PF: Assessing frontal lobe behavioral syndromes with the Frontal Lobe Personality Scale. Assessment 1999, 6(3):269-284.

66. Stout JC, Ready RE, Grace J, Malloy PF, Paulsen JS: Factor analysis of the Frontal Systems Behavior Scale (FrSBe). Assessment 2003, 10(1):79-85.

doi:10.1186/2047-9158-3-12

Cite this article as: Miller et al:: Randomized controlled trials in frontotemporal dementia: cognitive and behavioral outcomes.

Translational Neurodegeneration 2014 3:12.

\section{Submit your next manuscript to BioMed Central and take full advantage of:}

- Convenient online submission

- Thorough peer review

- No space constraints or color figure charges

- Immediate publication on acceptance

- Inclusion in PubMed, CAS, Scopus and Google Scholar

- Research which is freely available for redistribution 